\title{
DETERMINAÇÃO DE OBJETIVOS EDUCATIVOS
}

Sossar, J. A. - Determinação de objetivos educativos. Rev. Saúde públ., S. Paulo, 8:437-42, 1974.

RESUMo: São analisados aspectos teóricos relacionados à determinação de objetivos educativos e à questão das técnicas de redação operacional de objetivos. Pretende-se destacar apenas alguns aspectos relevantes relacionados ao problema.

UNITERMos: Educação*; Objetivo educativo*; Objetivo operacional*.

\section{I N T RODU C A O}

Um objetivo educativo adequadamente enunciado deve ser operacional. $O$ que caracteriza um objetivo operacional é a precisão. Um objetivo bem redigido deve indicar claramente um comportamento esperado numa dada situação, de maneira que qualquer pessoa possa identificar se o comportamento pretendido foi ou não adquirido. Em outras palavras, um objetivo educativo deve indicar um comportamento passível de avaliação.

\section{NfVEIS DE OBJETIVOS}

Objetivos operacionais referem-se a situações tão específicas que, se analisados isoladamente, não apresentam a unicidade que deve caracterizar os objetivos de um programa educativo. $O$ educador poderia levantar questões como:
- qual a importância de tal objetivo em um dado programa?

- como se coordenam os objetivos com vistas a uma meta final?

Para se ter uma visão dos objetivos de um programa como um todo e para se indicar comportamentos finais, costuma-se redigir também objetivos gerais. Como as metas gerais de um programa geralmente implicam em processos mais complexos, dificilmente será possível redigir objetivos gerais de maneira operacional.

Para que se possa avaliar se os objetivos gerais de um programa foram atingidos é necessário que eles sejam operacionalisados através de outros objetivos, isto é, deve-se indicar que comportamentos devem ser apresentados que evidenciem a consecução de cada objetivo geral. Exemplo:

* Da Disciplina Educação em Saúde Pública do Departamento de Prática de Saúde Pública da Faculdade de Saúde Pública da USP - Av. Dr. Arnaldo, 715 - São Paulo, SP - Brasil 
SosSAI, J.A. - Determinação de objetivos educativos. Rev. Saúde públ., S. Paujo, 8: $437-42,1974$.

Objetivo geral: As gestantes deverāo compreender a importância da alimentaçāo adequada durante a gravidez.

Objetivos específicos:

1. As gestantes deverão citar três razōes porque devem ingerir os alimentos $\mathrm{X}$ e $\mathrm{Y}$ durante a gravidez.

2. As gestantes deverão ingerir os alimentos $\mathrm{X}$ e $\mathrm{Y}$ duas vezes por semana.

3. Em conversa com as amigas, as gestantes deverão mencionar seus conhecimentos a respeito da importância da ingestāo dos alimentos $\mathrm{X}$ e $\mathrm{Y}$ durante a gravidez.

Se tomarmos cada um dos objetivos específicos citados. podemos verificar que indicam comportamentos mensuráveis que as gestantes devem apresentar em determinada fase de um programa. Parece, entretanto, que cada objetivo tomado isoladamente não tem razão de ser. Se convercionarmos que os três comportamentos sugeridos nos objetivos específicos indicam uma compreensão satisfatória da importância da alimentação adequada durante a gravidez, pode-se afirmar:

A maioria dos autores concorda em que um objetivo operacional deve ser redigido em termos da população alvo e não
- que têm sentido dentro de um programa;

- que a consecução dos objetivos específicos evidenciam a consecução do objetivo geral.

3. TÉCNICAS DE REDAÇAO OPERACIONAL DE OBJETIVOS

A redação de objetivos de maneira operacional pode ser facilitada pela utilização de algumas técnicas.

Sabemos que um objetivo operacional deve incluir sempre um comportamento que é expresso por um verbo. Exemplo: citar. ingerir, mencionar. Além disso, o comportamento deve sempre referir-se a algum objeto ou conteúdo. Citar o que? Ingerir . o que? Mencionar o que? Os dois elementos básicos de um objetivo operacional são. portanto, comportamento e conteúdo. Exemplos:

- A gestante deverá enumerar (comportamento) cinco causas de anemia (conteúdo).

- A gestante deverá ingerir (comportamento) os alimentos $X \in Y$ (conteúdo).

em termos de quem pretende a mudança de comportamento. Exemplos:
Em termos da população alvo

- A gestante deverá enumerar

- A gestante deverá ingerir ...

O termo "gestante" indica a populaça alvo, isto é, quem deve adquirir ou apresentar os comportamentos esperados. Esta é a maneira correta de redigir objetivos.
Em termos de quem pretende a mudanç $\alpha$

- Levar a gestante a enumerar

- Fazer com que a gestante ... Os termos "levar" e "fazer" referem-se a quem pretende provocar a aquisição ou a mudança de comportamento. Esta maneira de redigir objetivos não é correta. 
SOSSAI, J.A. - Determinação de objetivos educativos. Rev. Saúde públ., S. Paulo, 8: 437-42, 1974.

Outra técnica utilizada para tornar a redação de um objetivo operacional mais precisa é a explicitação da situação e da adequação.

A situação indica em que circunstância deve ser apresentado um comportamento. Retomando um dos exemplos já citados:

Em conversa com as amigas, as gestantes deverão mencionar seus conhecimentos a respeito da importância da ingestão dos alimentos $\mathrm{X}$ e $\mathrm{Y}$ durante a gravidez.

Situação: "Em conversa com as amigas. ."

A adequação indica com maior precisão em que nível consideramos satisfatório um comportamento para se admitir como atingido um objetivo. Exemplo:

$30 \%$ das gestantes da cidade $A$ deverão participar do programa de educação alimentar para gestantes.

Adequação: "30\% das gestantes. ."

Exemplo incluindo situação e adequação:

Dado um texto, as gestantes deverão identificar as razōes porque a gestante deve ingerir os alimentos $\mathrm{X} e$ $\mathrm{Y}$, com $80 \%$ de exatidão.

Situação: "Dado um texto. ."

Adequação: ". . com $80 \%$ de exatidão".

Neste caso, espera-se que as gestantes indiquem as razões em um texto, e não através de pesquisa de campo, em trabalho de grupo ou em consulta a especialistas.
Se o texto apresenta dez razões, por exemplo, considera-se satisfatória a identificação de 8 razões, isto é, $80 \%$. Quando não se menciona a adequação, está sempre implicito que o nível de aceitação é $100 \%$.

Os verbos utilizados na redação de objetivos para indicar o comportamento esperado, podem ser mais ou meros precisos. Não há um critério para se estabelecer quais termos são precisos e quais são imprecisos. Na redação operacional de objetivos devemos utilizar os verbos que indicam com maior precisão o comportamento esperado. $O$ seguinte rol de palavras permite uma comparação entre termos que indicam comportamentos com maior e com menor precisão:

\begin{tabular}{|l|l|}
\hline $\begin{array}{c}\text { Termos menos } \\
\text { precisos } \\
\text { (várias }\end{array}$ & $\begin{array}{c}\text { Termos mais } \\
\text { precisos } \\
\text { (sentido mais } \\
\text { preciso) }\end{array}$ \\
interpretaçōes) & Definir \\
Conhender & Relacionar \\
Pensar & Comparar \\
Entender & Resumir \\
Saber & Enumerar \\
Motivar & Selecionar \\
Captar & Ingerir \\
Compreender & Participar \\
\hline
\end{tabular}

Utilizando corretamente as técnicas de redação operacional de objetivos poderemos com maior facilidade indicar comportamentos mensuráveis, o que é fundamental para a avaliação e reformulação de um programa educativo.

\section{AREAS DE COMPORTAMENTO}

Com base na concepção de que o homem primeiramente conhece, depois aceita e por fim age, costuma-se dividir os objetivos educativos em três áreas: cognitiva, afetiva e ativa. Embora esta divisão não tenha fundamento rigorosamente 
SOSSAI, J.A. - Determinação de objetivos educativos. Rev. Saúde públ., S. Paulo, 8: $437-42,1974$.

científico, tem sido adotada em larga escala por educadores.

Os objetivos cognitivos incluem desde a simples evocação de material aprendido até a combinação e sintetização de novas idéias e materiais. Os comportamentos na área cognitiva são expressos por verbos como: relacionar, comparar, interpretar, distinguir, resumir, enumerar.

Os objetivos afetivos referem-se ao grau de aceitação ou de internalização de um conceito, comportamento ou fato. Refere-se a uma atitude ou sentimento em relação a alguma coisa. Os comportamentos na área afetiva são expressos por verbos como: aceitar, responsabilizar-se, reconhecer, perceber, tolerar, apreciar.

Os objetivos ativos referem-se a alguma atividade ou prática que deve ser adotada. Geralmente envolvem uma atividade motora. Os comportamentos na área ativa são expressos por verbos como: construir, confeccionar, escrever, ingerir, participar, distribuir, organizar, cooperar *

Segundos os teóricos, um programa educativo bem elaborado deve conter objetivos nas três áreas. Várias questões, entretanto, podem ser levantadas:
- Os objetivos cognitivos podem ser avaliados em um nível teórico, ou, como se costuma dizer, a nível de sala de aula. Ora, a aquisição de um comportamento na área cognitiva nem sempre é garantia de que o indivíduo será capaz de aplicar o conhecimento adquirido numa situação prática, que é o que se pretende em última análise.

- Os objetivos afetivos não podem ser avaliados diretamente, mas sim através dos objetivos cognitivos ou ativos. Pergunta-se então: qual a finalidade destes objetivos num programa educativo?

- A aquisição de uma prática é geralmente demonstrada na vida "fora da escola". Por isso, os objetivos ativos não podem ser facilmente avaliados em situação de sala de aula, e esta é a "situação educativa" mais freqüente.

Na prática o que pode ocorrer é o seguinte: o educador inclui no planejamento de um programa alguns objetivos na área cognitiva e admite "a priori" que o educando, conhecendo certas coisas, vai aceitá-las e adotar práticas relativas aos conhecimentos adquiridos. Este, aliás, tem sido um pressuposto admitido ao longo de toda a história da educação.

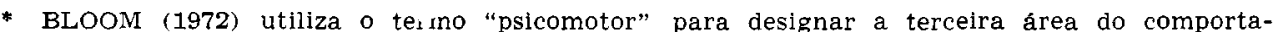
mento. Para este autor os objetivos psicomotores "enfatizam alguma habilidade muscular ou motora, alguma mantpulação de material e objetos ou algum ato que requer coordenaçāo neuromuscular (pág. 5)". De acordo com esta conceituação, o termo "ativo" para designar a terceira área do comportamento, como o definimos aquí, náo concorda exatamente com a conceituação do autor citado. Por outro lado, pouco mais adiante o mesmo autor afirma: “... a avaliação dos resultados da aprendizagem tem envolvido técnicas para apreciar pensamento, sentimento e ação (pág. 6)". O termo "psicomotor" ou psicomotricidade é substituido por "ação", o que dá margem a se supor que um equivale ao outro.

Este ponto, portanto, não parece estar muito claro. Além disso, se na situação de sala de aula objetivos psicomotores, como são definidos por Bloom, apresentam certa relevância, parece que o mesmo não ocorre em Educação em saúde. Neste campo o que se pretende é a adoção de práticas. Sabemos ainda que o ser humano funciona como um todo e não ocorre uma ação que não seja comandada pelo psiquismo. Neste sentido toda ação ou atividade é "psicomotora".

Por isso julgamos ser mais adequado utilizar o termo "ativo" ao invés de "psicomotor" para designar a tercelra área do comportamento quando estamos tratando de Educação em Saúde e definir um comportamento nesta área como implicando na adoção de uma prática. 
SOSSAI, J.A. - Determinação de objetivos educativos. Rev. Saúde públ., S. Paulo, 8: 437-42, 1974.

5. SELECaO E COORDENACAO VERTICAL DOS OBJETIVOS

Em educação deve-se partir do conhecido para o desconhecido, do simples para o complexo, do concreto para o abstrato. Este é um princípio elementar de psicologia da aprendizagem.

Um programa educativo bem estruturado deve conter objetivos que indiquem comportamentos a serem adquiridos numa ordem de dificuldade, desde os mais fáceis até os mais difíceis. Desta maneira, o comportromento será modelado tendo-se em vista as metas finais.

A coorclenação vertical dos objetivos assim entendida supõe não só o domínio de principios teóricos, mas requer a aplicação repetida e controlada de um programa. É através da experiência que se pode verificar em que medida a ordem em que são esperados os comportamentos é adequacla para determinada população.

Uma questão à parte da técnica de redação e dos princípios de organização dos objetivos num programa educativo, refere-se cos critérios de seleção de objetivos. A seleção de objetivos deve partir da análise do que se pretende com um programa e das condições em que será desenvolvido. Este aspecto não pode ser esquecido, do contrário poderemos elabo- rar objetivos tecnicamente perfeitos mas que não apresentam nenhuma relevância para uma dada situação.

\section{6. $\mathrm{CONCLUS \AA O}$}

Embora tenhamos discutido apenas alguns aspectos teóricos relativos à determinação de objetivos educativos, pode-se concluir que esta é uma questão extremamente importante quando nos referimos a planejamento de programas educativos. Pode-se também fazer algumas inferências sobre as relações entre objetivos educativos, metodologia de ensino, critérios e instrumentos de avaliação.

Em relação à determinação de objetivos educativos, acreditamos que o domínio das técnicas de redação e a aplicação de alguns princípios para seleção e organização dos objetivos em um programa, tornarão mais fácil a aquisição de comportamentos desejáveis e a mudança de comportamentos inadequados.

A adoção de práticas adequadas em relação à determinação de objetivos de um programa educativo não deve ser motivada por uma necessidade de satisfazer exigências teóricas, mas pela convicção de sua função produtiva. Isto implica aquisição de conhecimentos, mudança de atitudes e adoção de práticas.

RSPU-B/237

SossaI, J. A. - [Stating educational objectives.] Rev. Saúde públ., S. Paulo, 8:437-42, 1974.

SUMmaRY: Theoretical aspects related to stating objectives and the techniques for stating behavioural objectives are analysed. The intention is to emphasize only some of the relevant aspects related to the problem.

UNITERMS: Educational objective*; Behavioral objective*. 
SosSAI, J.A. - Determinação de objetivos educativos. Rev. Saúde públ., S. Paulo, 8: 437-42, 1974.

\section{REFERENCIAS BIBLIOGRAFICAS}

1. BLOOM, B.S, et al. - Taxonomia dos objetivos educacionais, 1 - Domínio cognitivo. Porto Alegre, Ed. Globo, 1972 .

2. BLOOM, B.S. et al. - Taxonomia dos objetivos educacionais. 2 - Dominio afetivo. Porto Alegre, Ed. Globo, 1972 .

3. GARCIA, L.O. - La Redacción de objetivos en terminos de conducta obser. vable. Universidad de Puerto Rico, Facultad de Pedagogia, 1970.
4. MAGER, R.F. - Preparing objectives for programmed instruction. San Francisco, Fearon Publishers, 1961.

5. POLLOCK, M.B. - Behavioral objectives: a process approach to health education. Intern. J. Hlth. Educ., 13:27-35, 1970 .

Recebido para publicação em 18/9/1974

Aprovado para publicacão em 4/10/1974: 